\title{
Construction of a Wireless Smart Home System based on Voice Recognition
}

\author{
Edema, Misan Markson \\ Department of Electrical/Electronic Engineering \\ University of Port Harcourt, PMB 5323 Choba, East West Road, Port Harcourt
}

\begin{abstract}
In this paper a design and construction of a wireless smart home system on voice recognition has been presented. The proposed system consists of a voice recognition module, Arduino Uno microcontroller, relay circuit and radio frequency transmitter and receiver. The voice recognition module needs to be trained first before it can be used to recognize commands. Upon successful recognition of voice command, the Arduino drives the corresponding load with the help of the relay circuit.
\end{abstract}

Keyword: Wireless, smart home system, voice recognition

DOI: $10.7176 /$ ISDE/10-1-01

\section{INTRODUCTION}

Speech recognition have a wide range of application in telecommunication, automobile, military, aviation, training air traffic controller, telephony and other domains, usage in education and daily life etc. . Speech recognition systems has made it possible to have what is often referred to as a "smart home", a home that can detect and identify you voice automatically adjust the lighting to your predefined taste, open doors automatically, water your flower in the morning, switch on the security lights at night and switch them off in the morning, heat water for bathe and tea, stream to you anywhere in the world via the internet a live video of what is happening in around your house. It makes it possible to link lighting, entertainment, security, telecommunication, heating and air conditioning into centrally controlled system. This allows you to make your house an active partner in managing your busy life.

The Concept of Home automation has been around since the late 1900s. (, [4], [5], [8], [10]) implemented a home automation system using Bluetooth that can be accessed remotely through GPRS. [1] Implemented a home automation system using SMS. [2] Implemented a home automation system using Internet for enabling remote home access and infrared technology for device communication within the home. [6] Also implemented a home automation Security System called Smart-Eye using General Packet Radio Service (GPRS). [7] Implemented a DTMF-based home automation system in which the user calls a SIM number assigned to the home and presses the digits on their phone's keypad to control the home's devices by generating a DTMF tone.

Automation has been around since the World War 1 [1914], in fact, the television remote (a simple home automatic system) was patented in 1893. Speech recognition is the process by which a computer (or other type of machine) identifies spoken words. Basically, it means a human talking to the computer, and having it correctly recognize what the human is saying. Results have been encouraging, and voice applications have included: control of communication radios, setting of navigation systems, and control of an automated target handover system ([3], [9]). Speech recognition can be useful for learning a second language. It can teach proper pronunciation, in addition to helping a person develop fluency with their speaking skills. By saying the words aloud, they can increase the fluidity of their writing, and be alleviated of concerns regarding spelling, punctuation, and other mechanics of writing. Here in this research, we designed and constructed a wireless smart home system using voice recognition.

\section{SYSTEM MODEL}

The research is a microcontroller based study where speech can be used to control devices. The command is imputed by means of a voice recognition device interfaced with an Arduino Uno module. This imputed command is transmitted by the RF transmitter interfaced with the Arduino module to the RF receiver which is also interfaced with another Arduino module at the receiving end. An 8-way Relay which functions as a switch is interfaced with the Arduino module at the receiving end that puts on and off the load connected to each of the relay according to the given command. The block diagram is shown below. 


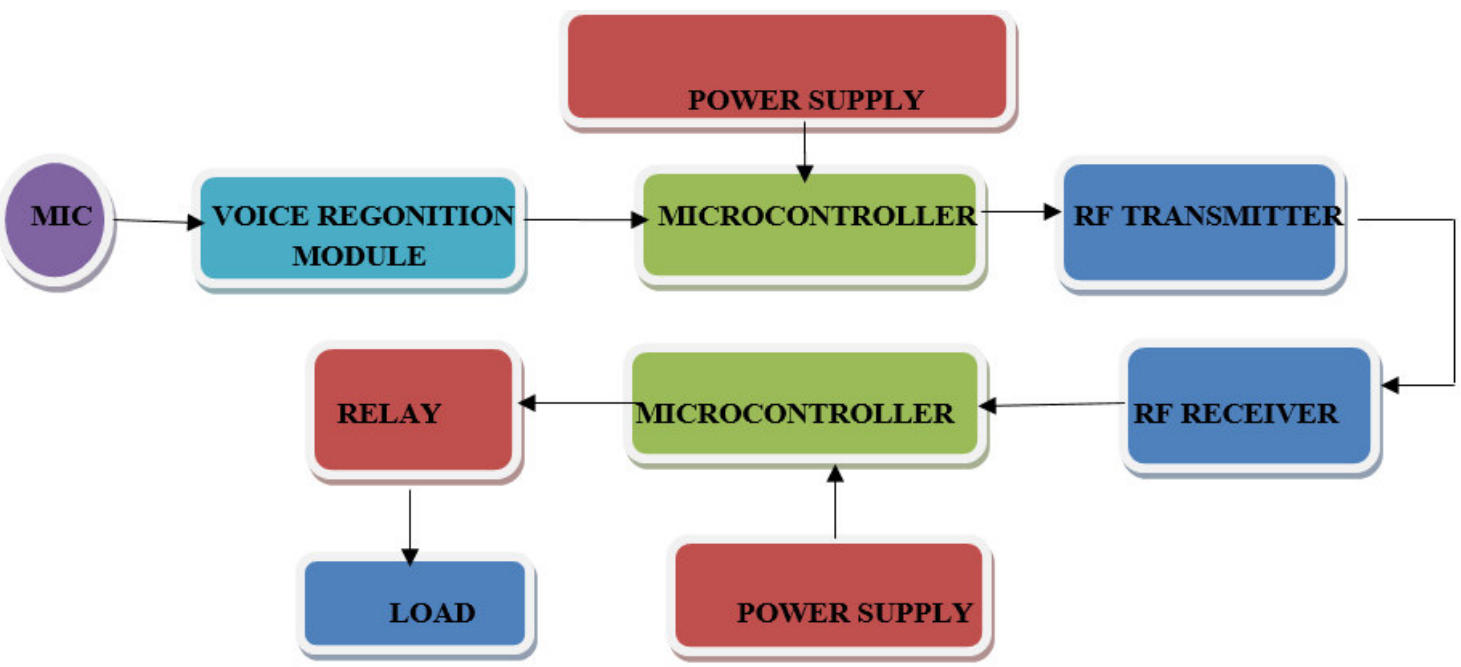

Figure 1: Block Diagram of the Voice Control System

The circuit made use of an embedded system and wireless module in controlling several loads. The design is made up of the software and hardware part. The hardware parts consist of the following, the power supply unit, the microphone unit (voice Recognition module), the transmitting Microcontroller (Arduino), RF transmitter, RF receiver, the receiving Microcontroller (Arduino), and Relay

\subsection{DESIGN ANALYSIS}

The circuit diagram will be explain below based on the power supply unit, input unit, control unit and the output unit.

The power supply unit

This supplies power to the whole circuit. It serves as the main source of power supply to the circuit as well as the output units. It is made up of the power supply unit. It consists of the following component,

i. Transformer12v-0v-12v

ii. Bridge rectifier

iii. Capacitor

iv. $\quad$ Voltage regulators

v. Indicators

vi. Resistor.

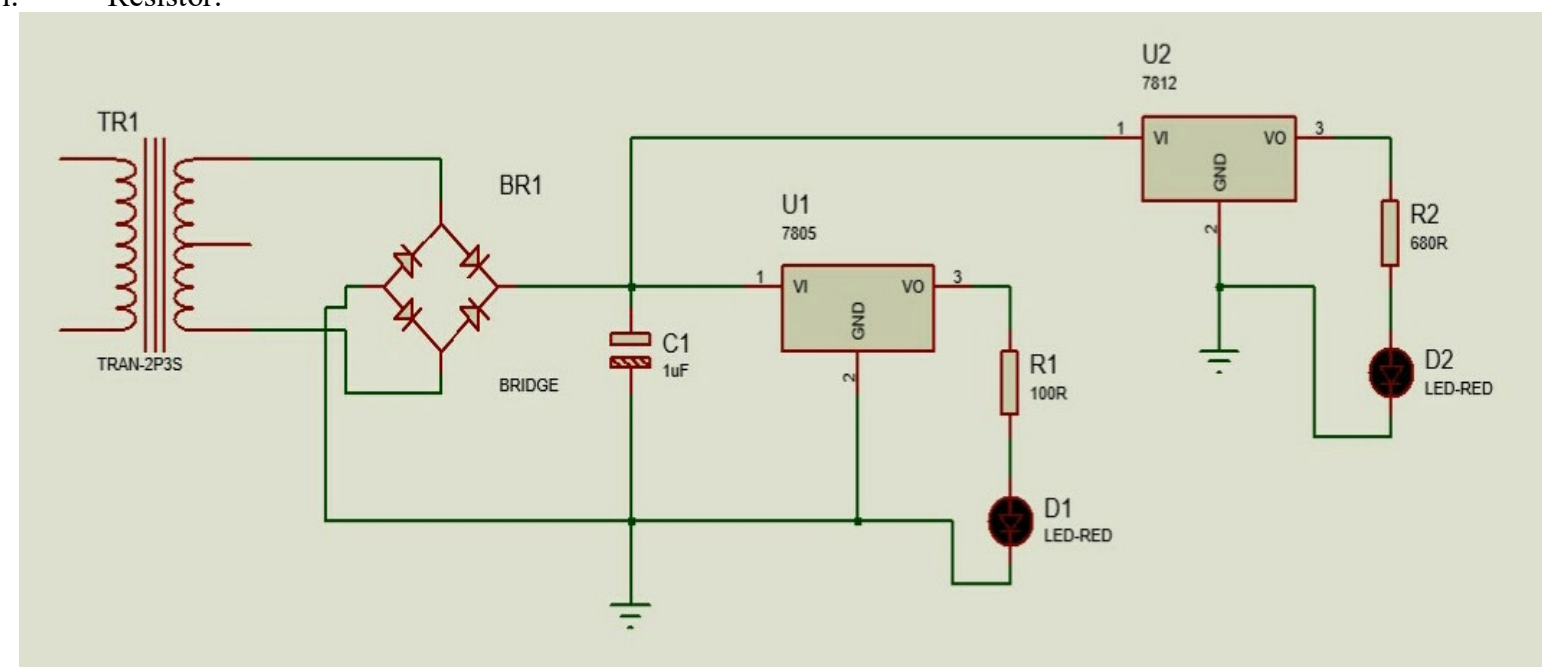

Figure 2: Circuit Diagram of the Power Supply.

The power supply unit is made up of the step down transformer (TR1), which step down the 220Vac supply to $24 \mathrm{Vac}$. The ac is converted to dc by a bridge rectifier (BR1). The dc voltage is filtered by using a filter capacitor $(\mathrm{C} 1)$, the filter capacitor is used to filter off any ac ripples in the dc voltage. The voltage from the filter capacitor is an unregulated voltage, the voltage required by the circuit is $5 \mathrm{Vdc}$ and $12 \mathrm{Vdc}$, two voltage regulators was used to supply constant voltage, 7805 voltage regulator (U1) outputs $5 \mathrm{Vdc}$ and 7812 voltage regulator 
outputs (U2) 12Vdc. two light emitting diode (D1 and D2) are also used as a power indicator for the 5Vdc and $12 \mathrm{Vdc}$ regulators. The resistors R1 and R2 are used to limit the current flowing through the light emitting diodes. Micro phone and the Voice recognition device

The input unit is made up of the Micro phone and the Voice recognition device (Ultrasonic sensor).

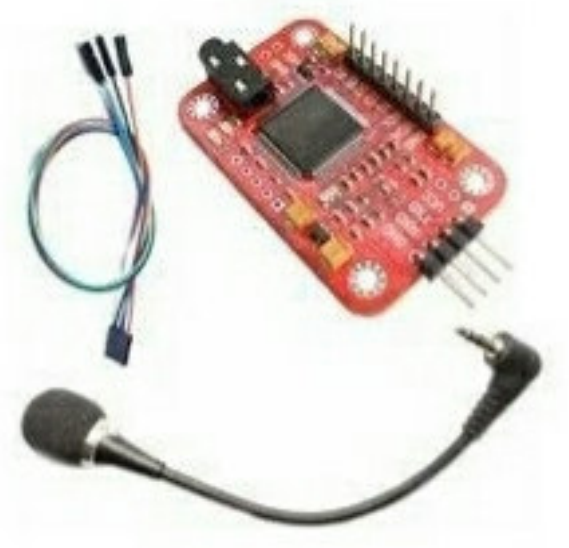

Figure 3: Diagram of Voice recognition module

The Ultrasonic processing is similar to radar. The Ultra high frequency acoustic tone is thrown at a moving object, the reflection produced are recorded by a receiver. The Doppler effect governs the frequency of the tone reflected, the equation for it can be expressed as:

$\mathrm{F}=\mathrm{F}_{\mathrm{O}}(1+\mathrm{Vc})$

Where

$\mathrm{F}_{\mathrm{O}}=$ emitted tone frequency

$\mathrm{F}=$ reflected tone frequency

$\mathrm{V}=$ velocity of reflecting surface towards the emitter

$\mathrm{c}=$ speed of sound

The voice recognition module was designed for the purpose of receiving commands from the human voice. It has a transducer (microphone) that converts the sound energy into an electrical energy. The electrical signal is converted into binary bits by the module and the output is sent to the microcontroller

Microcontroller (Arduino Uno ATmega328p)

The microcontroller used is an Arduino Uno ATmega328p, is an open source platform used for building electronics projects. Arduino consists of both a physical programmable circuit board (often referred to as a microcontroller and a piece of software, or IDE (Integrated Development Environment) that runs on your computer used to write and upload computer code to. the physical board.

Arduino does not need a separate piece of hardware (called a programmer) in order to load new code onto the board, you can simply use a USB cable. Additionally, the Arduino IDE uses a simplified version of C language, making it easier to learn to program. Finally, Arduino provides a standard form factor that breaks out the functions of the micro-controller into a more accessible package.

Arduino can interact with buttons, LEDs, motors. Speakers. GPS units, cameras, the internet and even your smart-phone or your TV! This flexibility combined with the fact that the Arduino software is free the hardware boards are pretty cheap, and both the software and hardware are easy to learn has led to a large community of users who have contributed code and released instructions for a huge variety of Arduino based projects The Arduino is the brains behind this project. 
Technical Specifications of an Arduino Uno

Table 1 Showing specifications of the Arduino

\begin{tabular}{|l|l|}
\hline Microcontroller & ATmega328 \\
\hline Operating voltage & $5 \mathrm{~V}$ input voltage (recommended) 7-12V input voltage (limits) \\
\hline Digital I/O pins & 14 (of which 6 are PWM output) \\
\hline Analog input pins & 6 \\
\hline PWM Digital I/O pins & 6 \\
\hline Dc current per I/O pin & $20 \mathrm{Ma}$ \\
\hline Dc current for 3.3V pin & $50 \mathrm{Ma}$ \\
\hline EEPROM & $1 \mathrm{~KB}$ \\
\hline SRAM & $2 \mathrm{~KB}$ \\
\hline Clock speed & $16 \mathrm{MHz}$ \\
\hline Flash memory & $32 \mathrm{~KB}$ of which $0.5 \mathrm{~Kb}$ used by bootloader \\
\hline Length & $\mathbf{6 8 . 6 m m}$ \\
\hline
\end{tabular}

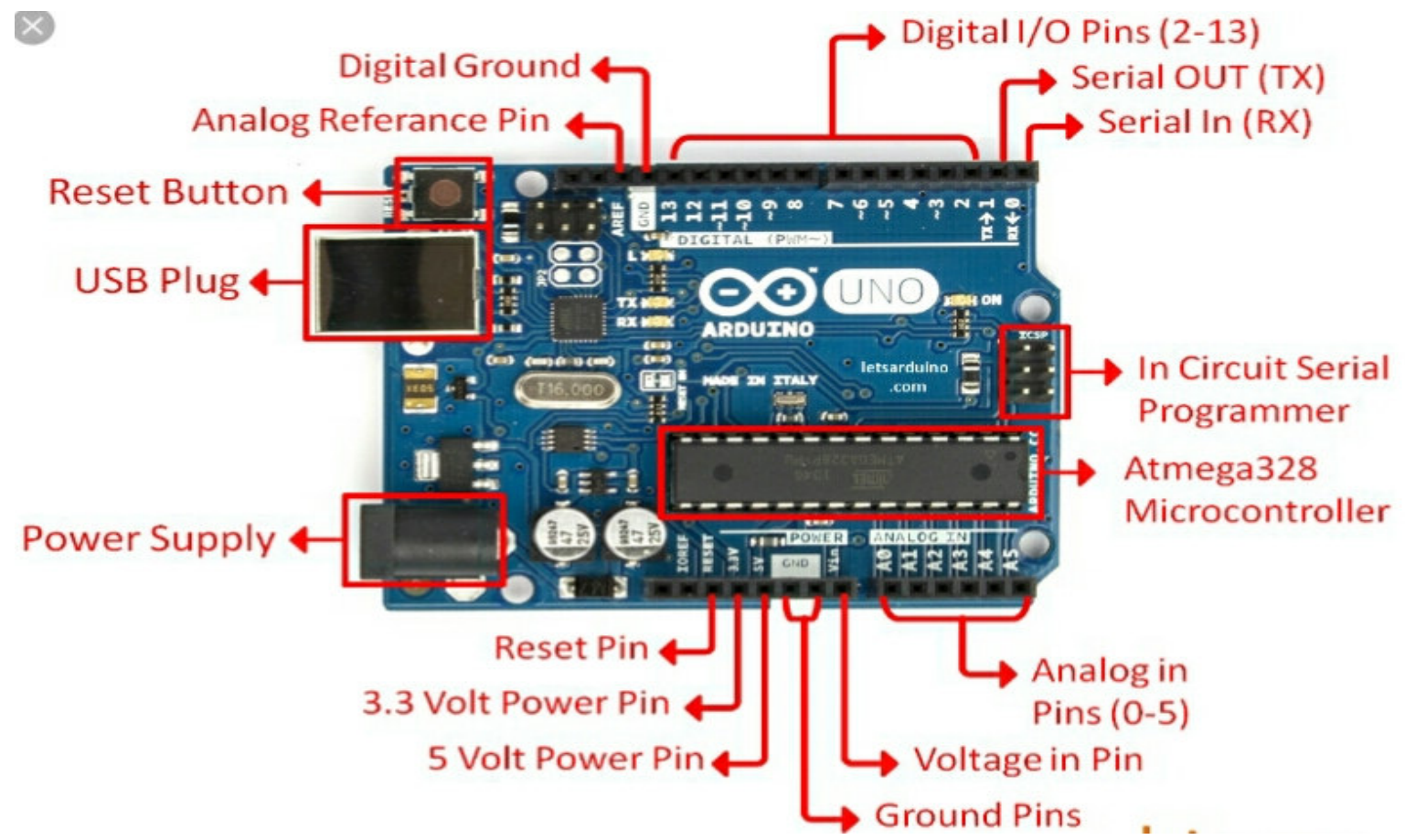

Descriptions of an Arduino Uno ATmega328p.

\section{A. Arduino Digital Pins}

In addition to the specific functions listed below, the digital pins on an Arduino board can be used for general purpose input and output via the pin Mode, digital Read and digital Write commands. Each pin has an. internal pull-up resistor which can be turned, on and off using digital Write when the pin is configured as an input The maximum current per pin is $40 \mathrm{~mA}$.

- Serial: $U$ (RX) and 1(TX). used receive (RX) and transmit ('TX) TTL serial data.

- External Interrupts: 2 and 3 These pins can be configured to trigger an interrupt on a low value.

- PWM: 3, 5, 6, 9, 10, and11 Provide 8-bit PWM output with the analog write function. On boards with an ATmega328. PWM output is available only on pins 9, 10 and 11.

- $\quad$ BT Reset: 7. (Arduino BT-only) Connected to the reset line of the RF module.

- SPI: 10 (SS), 11 (MOSI), 12 (MISO), 13 (SCK). These pins support SPI communication, which, although provided by the underlying hardware, is not currently included in the Arduino language.

LED: 13. When the pin is HIGH value, the LED is on, when the pin is L0W, it's off

B. Analog Pins

In addition to the specific functions listed below the analog input pins support 10-bit analog-to-digital conversion (ADC) using the analog Read function. Most of the analog inputs can also be used as digital pins: analog input 0 as digital pin 14 through analog input 5 as digital pin 19 Analog inputs 6 and 
7(present on the Mini and BT) cannot be used as digital pins.

\section{Power Pins}

- VIN (sometimes labelled "9V". The input voltage to the Arduino board when it's using an external power source (as opposed to 5 volts from the USB connection or other regulated power source). You can supply voltage through this pin, or, if supplying voltage via the power jack. Access it through the pin.

- $\quad 5 \mathrm{~V}$. The regulated power supply used to power the microcontroller and other components on the board. This can come either from VIN via an on-board regulator, or be supplied by USS or another regulated $5 \mathrm{~V}$ supply.

- $\quad$ 3V (Diecimila-only) A 3.3 volts supply generated by the on-board FTDI clip.

- GND. Ground pins.

RF Transmitter modules

An RF Transmitter module is a small PCB sub assembly capable of transmitting radio have and modulating that wave to carry data. Transmitter modules are usually implemented alongside a micro controller(Arduino) which will provide data to the module which can be transmitted.

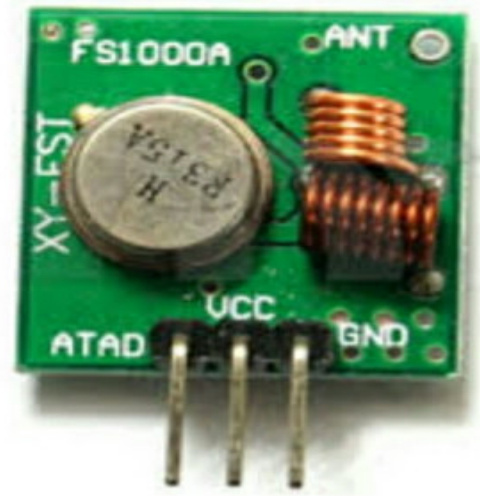

Figure 5: Diagram of RF Transmitter

RF Transmitters are usually subject to regulatory requirement which dictate the maximum allowable transmitter power output harmonies and band edge requirements.

Working voltage: $\quad 3 \mathrm{~V}-12 \mathrm{~V} \mathrm{~F}_{\mathrm{o}}$ max.power use $12 \mathrm{~V}$

Working current: max less than 40Ma max, and min 9mA

Resonance mode: $\quad$ (SAW)

Modulation mode: $\quad$ ASK

Working frequency: $\quad 315 \mathrm{MHz}-433.92 \mathrm{MHz}$

Transmitting power: $\quad 25 \mathrm{Mw}(315 \mathrm{MHz}$ at $12 \mathrm{~V})$

Frequency Error: $+150 \mathrm{KHz}(\max )$

Velocity: less than $10 \mathrm{kps}$

\section{RF Receiver Modules}

An RF receiver modules receivers the modulated RF signal, and demodulates it and are usually implemented alongside a microcontroller, which will provide data to the module.

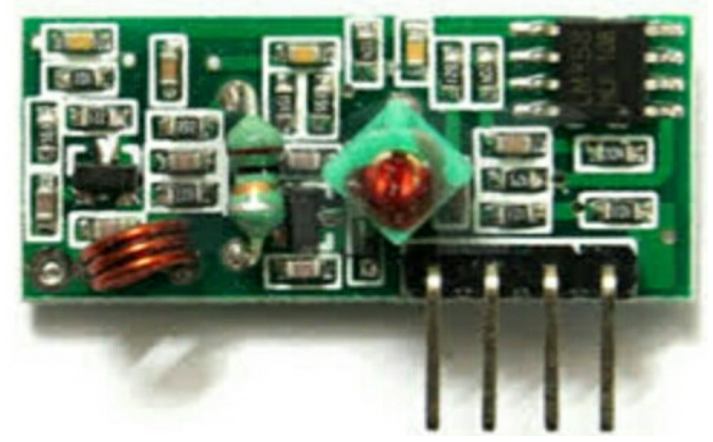

Working voltage: $5.0 \mathrm{VDC}+0.5 \mathrm{v}$

Figure 6: Diagram of RF Receiver

Working current: $\leq 5.5 \mathrm{~mA} \max$

Working method:

OOK/ASK 
Working frequency:

Bandwidth:

$315 \mathrm{MHz}-433.92 \mathrm{MHz}$

Sensitivity:

$2 \mathrm{MHz}$

excel $-100 \mathrm{dBm}(50 \Omega)$

Transmitting velocity: $<9.6 \mathrm{kps}$ (at $315 \mathrm{MHz}$ and $-95 \mathrm{dBm}$ )

The RF receiver/transmitter used in this project can cover a distance of $20 \mathrm{~m}$ with a frequency ranging from

Relay

A relay is usually an electromechanical device that is actuated by an electrical current. The current flowing in one circuit causes the opening or closing of another circuit. Relays are like remote control switches and are used in wide variety of application throughout industry, because of their relative simplicity. Long life and proven high reliability such as in telephone exchanges digital computer and automatic systems.

Relay are mainly used to protect electrical power system, on/off control, limit control and logical operation and are able to control the flow of current between a low-voltage circuit controls a high-voltage circuit. Relays also come in two different forms electromechanical Relay and the Solid State Relay.

In this paper I made use of an eight-way relay with voltage rating of $5 \mathrm{v}$, where each way is to control a particular output device. The main advantage of the electromechanical relay is because it permits to controls a large power in the load by a small power of the relay.

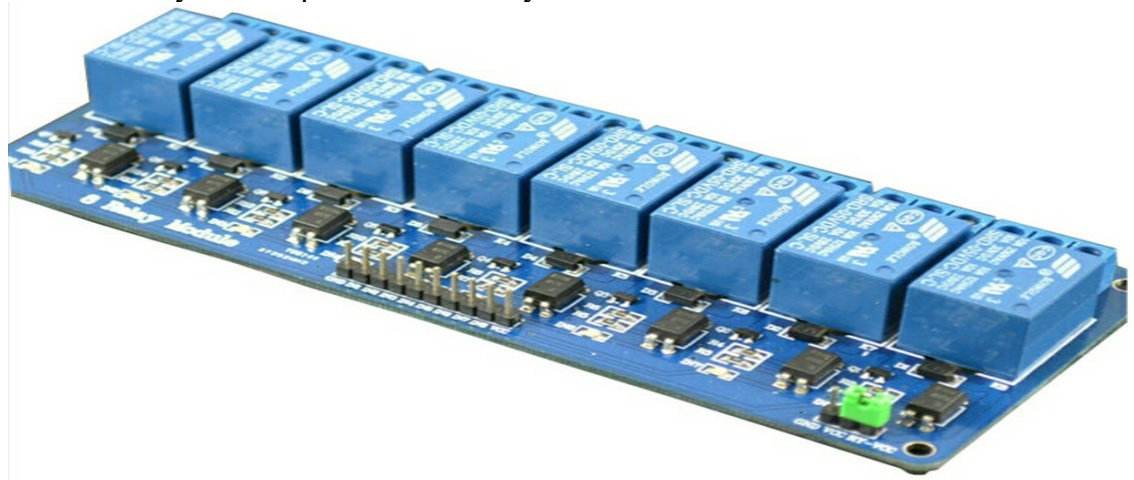

Figure 7: Diagram of an 8-way relay

\section{CONSTRUCTION AND ASSEMBLY OF COMPONENTS}

The circuit diagram shown in Figure 3.2 shows the voice control circuit diagram. The circuit diagram is explained below based on the power supply unit, microphone unit. (Voice Recognition module), the transmitting Microcontroller (Arduino), RF transmitter, RF receiver, the receiving Microcontroller (Arduino) and Relays.

The schematic of the circuitry was first design using Proteus VSM. Calculations were done based on the design and the component were purchased. construction work stated with the building of the power supply system by mounting the transformer and soldering the bridge rectifier on the PCB board, mounting the capacitor to smoothing the d.c and voltage regulator to regulate the voltage $5 \mathrm{v}$ and $12 \mathrm{v}$ placing an indicator to indicate the flow of the require voltage and the resistor to protect the LEDs. The RF module, the voice recognition module and the Arduino Uno were interface and tested and working in good condition. Then the work was package and reliability test carried out to ensure how reliable the work.

\section{Software Design}

The software used for this work are listed below.

a PROTEUS VSM (Virtual system modeling). This was used to achieve the construction prototype of the system. The schematics of the system starting from the power supply system to the main circuitry were designed using this software before the main construction work began.

The diagram is shown below 

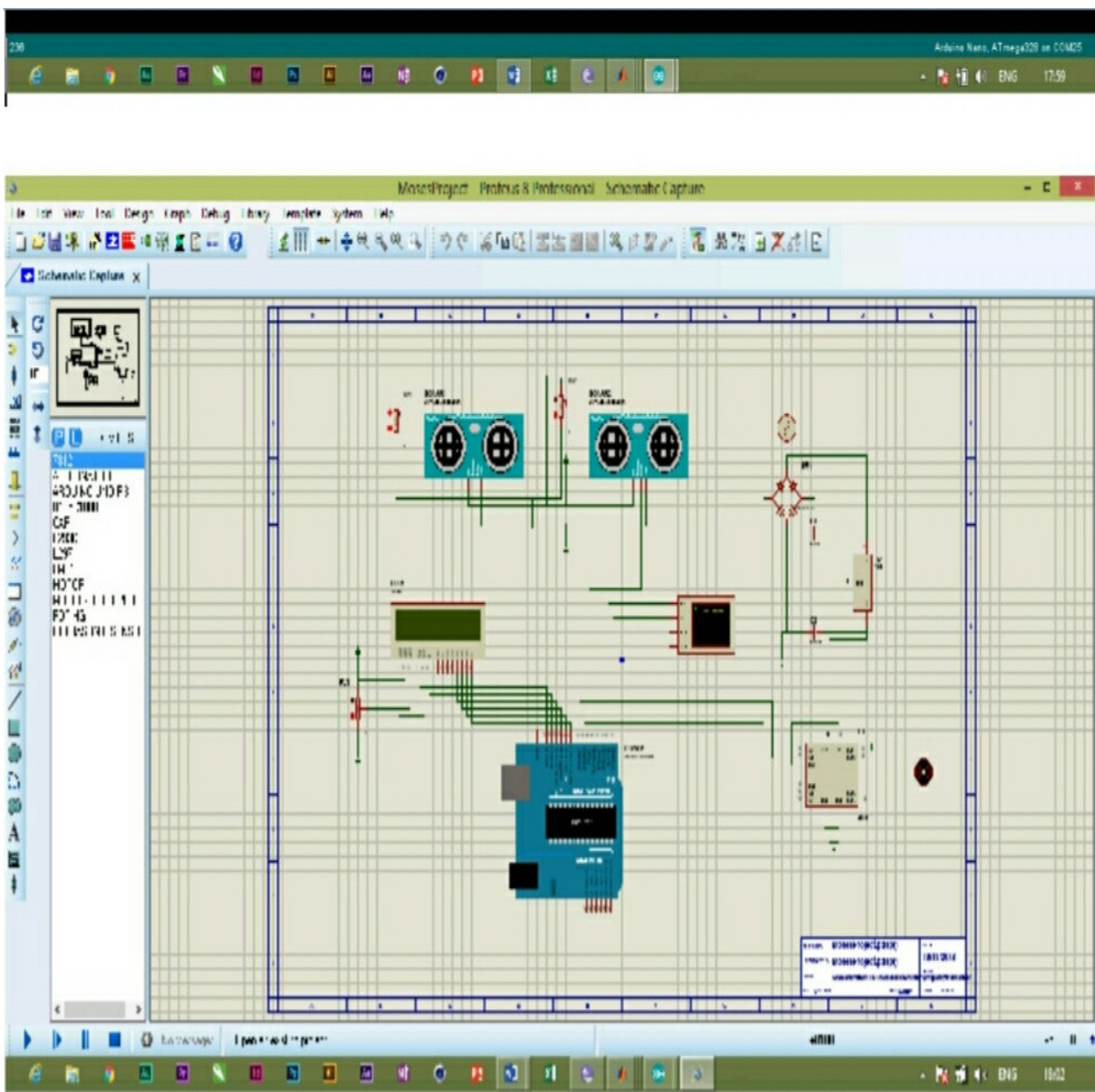

Figure 8: Interface of the Proteus working environment 


\section{CIRCUIT DIAGRAM}

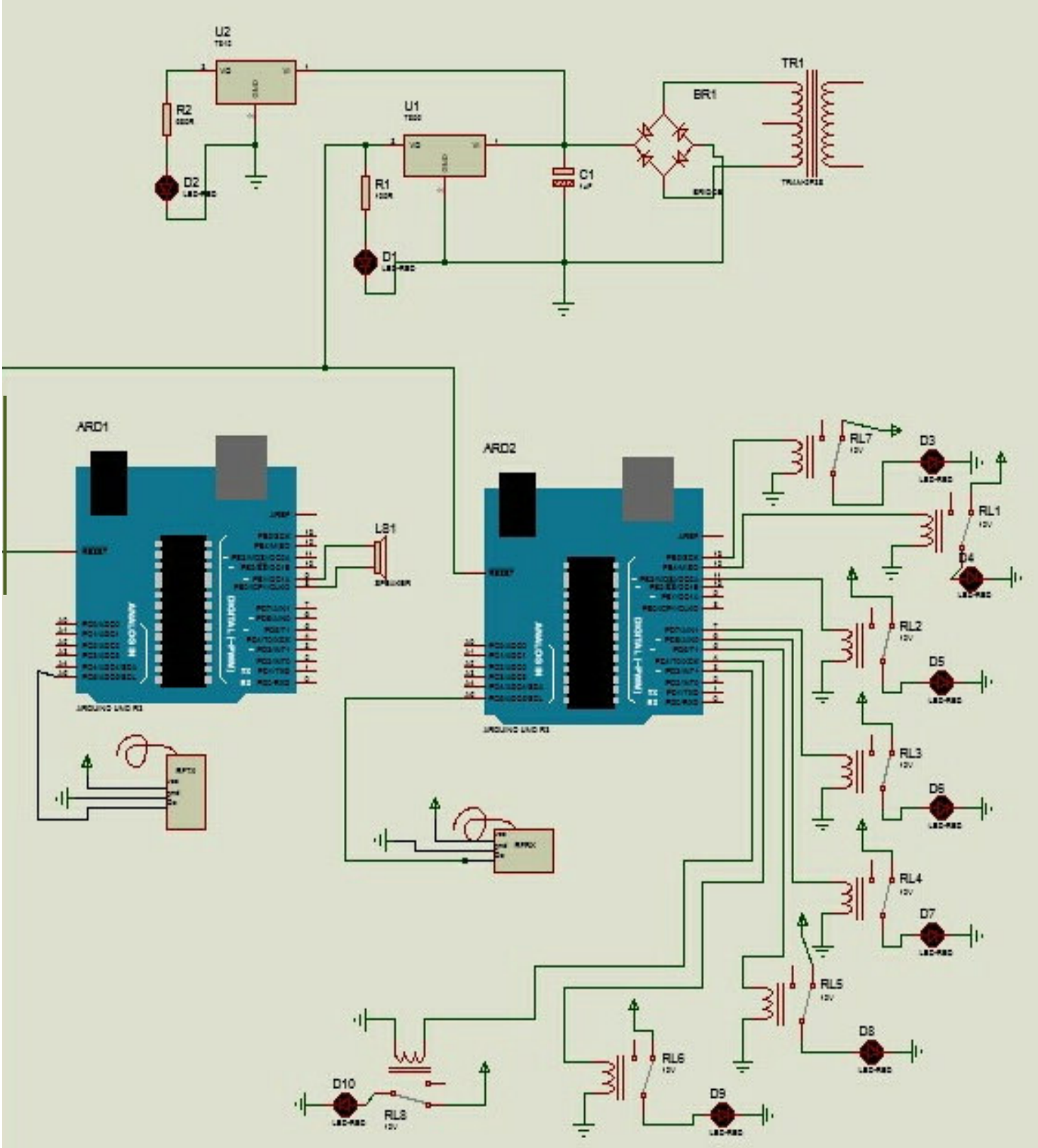

Figure 9: Circuit Layout of Microcontroller Based Voice Recognition Flowchart from the Transmitting End 


ISTE

Flowchart from the Transmitting End

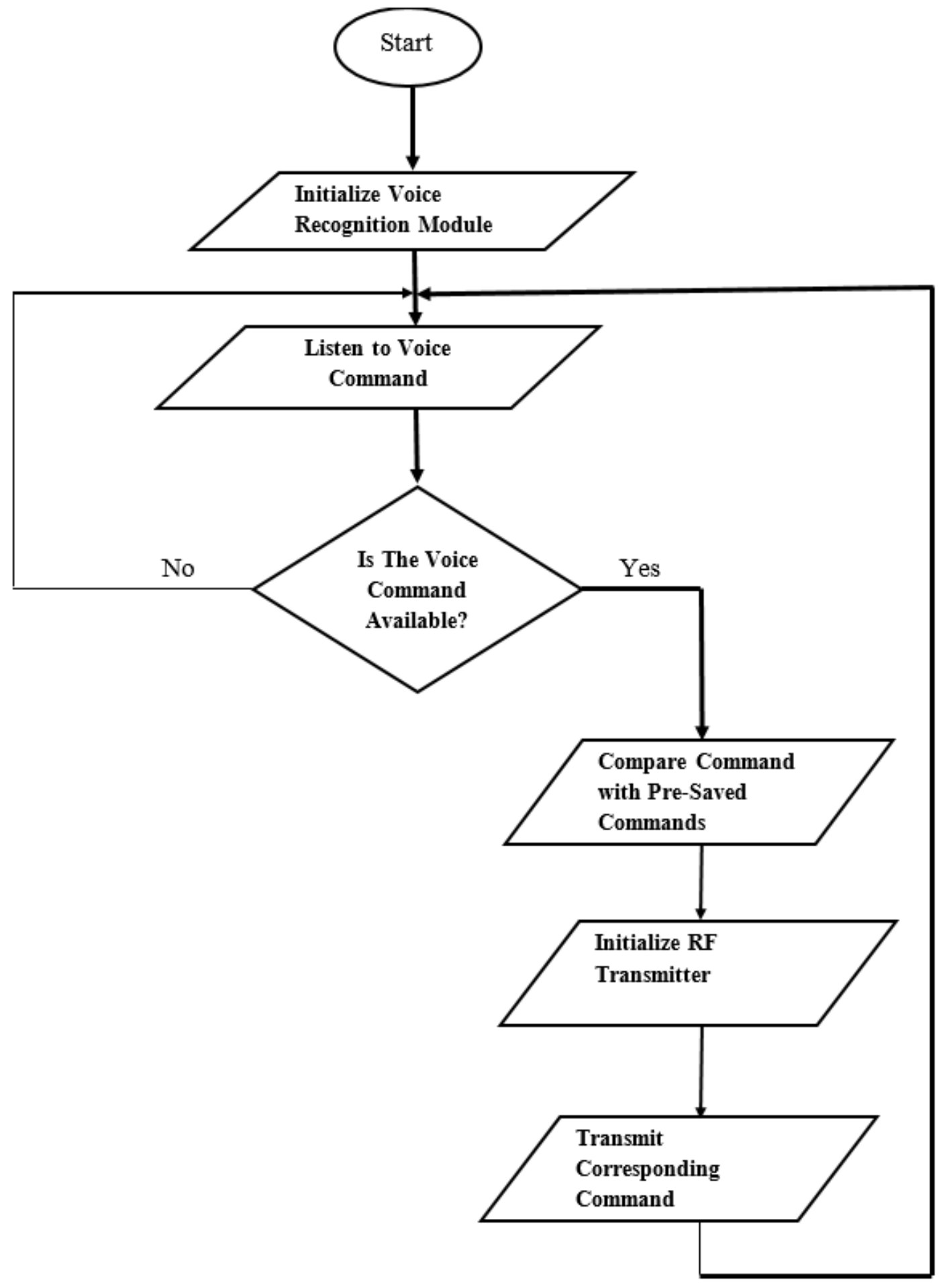


Flowchart for the Receiving End

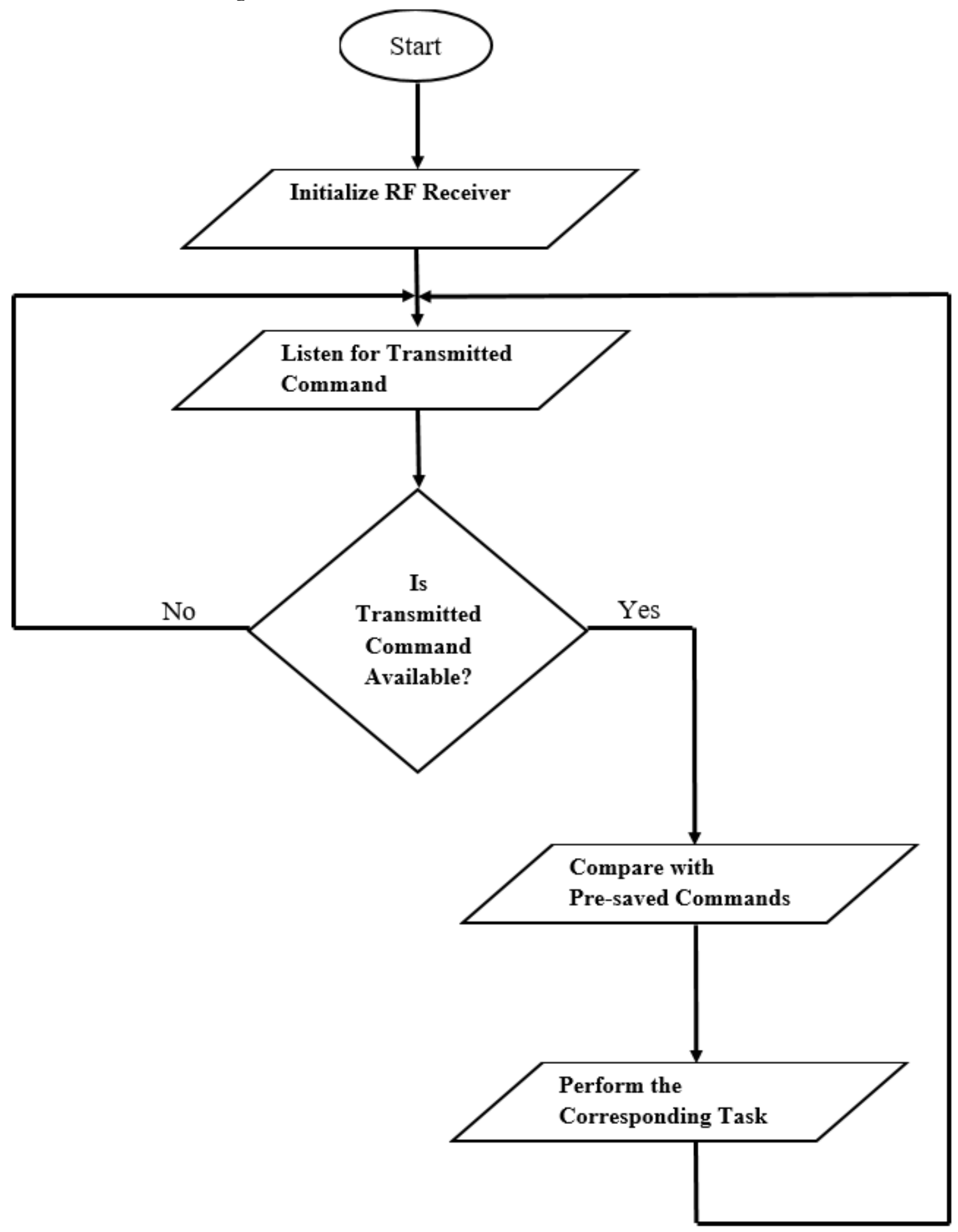

\section{CONCLUSION}

Construction of a Voice control system was of a truth a fascinating task to undergo. The climax of the whole process was to see that the hardware and software implementation are working as desired after several process of trial and adjustment. This paper has provided us a great deal of insight into the field of communication and control engineering. This paper was designed and constructed considering some factors such as economic applications, design economy, availability of components and research materials, efficiency, reliability, 
compatibility and also durability. However, the general operation of this work and performance is dependent on the user who is prone to human error such as careless handling or lack of adequate maintenance. Other factor that might affect performance includes packaging ventilation, quality of component, handling usage and transportation. The construction was done in such a way that it makes maintenance and repairs an easy task and affordable for the user, should there be any system breakdown. In general, this work can be found establishments such as banks restaurants, churches, colleges, airport and other organizations. It gives an alternative way of putting on/off electrical Appliances without going close to the switch.

\section{REFERENCE}

A. Alheraish, Design and Implementation of Home Automation System, IEEE Transection on consumer, 50(4) (2004): 10887-1092.

Alkar. Z and Buhur. U, An internet based wireless home automation system for multifunctional devices, IEEE consumer electronics, 51(4) (2005):1169-1175.

Arthi.J.E and M.Jagadeeswari, Control of Electrical Appliances through Voice Commands, IOSR Journal of Electrical and Electronics Engineering, vol. 9(2014):13-18.

Chakradhar, B., KrishnaveniI, S., and Naresh. D, "Bluetooth Based Home Automation and Security System Using ARM9", International Journal of Engineering Trends and Technology (IJETT), 4(9), 2013: 40534058.

H. Kanma, N. Wakaba Yashi, R. Kanazawa, H. Ito, Home appliance control system over bluetooth with a cellular phone, IEEE consumer electronics society, 49(4):1049-1053.

K. Atukorala, D. Wijekoon, M. Tharugasini, I. Perera, C. Silva, Smart eye integrated solution of home automation security and monitoring through mobile phones. IEEE, 2009: 64-69.

Lisa Muhury and Mohammed. A. Habib, Device control by using GSM network computer and

Information technology, ICCIT, 5th international conference, 2012, DOI: 10.1109/ICCITechn.2012.6509726

Ming Yan and Hao Shi "SMART LIVING USING BLUETOOTH BASED ANDROID SMARTPHONE" International Journal of Wireless \& Mobile Networks (IJWMN), 5(1), 2013: DOI: 10.5121/ijwmn.2013.5105 65 .

Mohamed Abd El-LatifMowad, Ahmed Fathy, Ahmed Hafez "Smart Home Automated Control System Using Android Application and Microcontroller” International Journal of Scientific \& Engineering Research, 5(5), 2014: ISSN 22295518

N. Sriskanthan, F. Tan and A. Karande. Bluetooth Based Home Automation System. Elsevier. 26(2002):281-289 